NOTICIAS Y DOCUMENTOS Rev Chil Salud Pública 2013 Vol 17 (2): 193-195

\title{
Declaración de Túnez - V Foro Social Mundial de la Salud y Seguridad Social \\ Posicionamiento del FSMS y SS sobre debate de cobertura universal de salud y Post-ODM 2015
}

Tunez Declaration

\section{Position of the V World Social Forum on Health and Social Security on the Universal Healthcare Coverage DEBATE AND POST-MDG 2015}

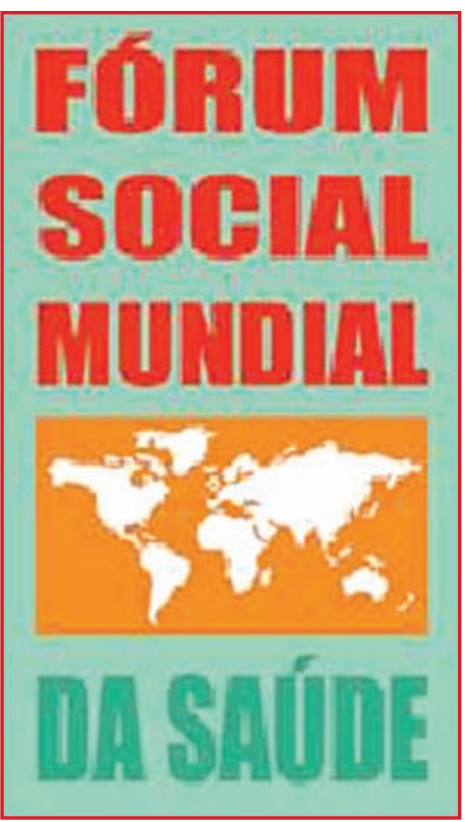

Los movimientos sociales, organizaciones de la sociedad civil y actores del campo popular miembros del Foro Social Mundial de la Salud y Seguridad Social como una más de las expresiones de las voces, rostros, sabidurías y conocimientos de los pueblos expresamos:

1- Que la crisis internacional del capitalismo es de carácter sistémico y civilizatorio. Expresadas en las economías y sociedades del norte geopolítico del planeta- Estados Unidos y Europa, donde sólo se han profundizado las recetas neoliberales, ajustes estructurales, destrucción de derechos y ciudadanías afectando ferozmente la calidad de vida saludable de sus pueblos. Es decir, la crisis no implica bajo los procesos políticos y sociales actuales pensar en un post-capitalismo ni en un sistemamundo postcolonial aunque abre serias grietas y rupturas expresadas por ejemplo en América Latina y el Caribe en procesos

que buscan un post-neoliberalismo con cambios y emancipación social.

2- Que la crisis internacional en su dimensión financiera demostró una decisión política internacional contundente: en menos de 2 semanas posteriores a la quiebra de Lemahn Brothers este sistema social vigente y los Estados más importantes como Estados Unidos y la Unión Europea hicieron salvatajes de miles de billones de dólares o euros al sistema financiero mundial (que aun hoy perduran y continúan), dejando en evidencia que con menos del $8 \%$ de lo invertido en esos momentos se podrían cumplir el 100\% de los Objetivos de Desarrollo del Milenio (ODM) para terminar con el hambre, la pobreza y las muertes evitables en el mundo. Es decir, este sistema social y formas de organización de nuestras sociedades de acumulación acelerada del capital, 
de mercantilización y destrucción de la vida claramente "salva Bancos y empresas multinacionales" pero no "salva vidas" incluyendo al propio ecosistema de la Madre Tierra en su desenfrenada voracidad y saqueo.

3- Que el debate abierto por el evidente no cumplimiento de los Objetivos de Desarrollo del Milenio, objetivos que fueron expresiones de lo "mínimo" y/o "básico" que ciertamente significaron una mirada monocultural de los modelos de desarrollos para la calidad de vida de los pueblos pero que nunca expresaron ni identificaron ni debatieron los intereses del statu quo y los responsables de las desigualdades, inequidades, pobrezas y exclusiones que priman en nuestro mundo. Los ODM ciertamente aunque significaron algunos avances en atención y respuesta a enfermedades olvidadas por el complejo médico-industrial farmacológico y los negocios del mercado de la salud, en gran medida potenciaron la fragmentación de nuestras agendas, luchas, sueños y respuestas desde los movimientos de sociedad civil y también de los propios Estados por la propia división de ODM para Género, para Agua y Saneamiento, o para daños en la salud como mortalidad infantil o materna o enfermedades como el VIH-SIDA. Cada uno de esos objetivos expresando agendas y políticas por separado, muchas veces condicionando el tipo de respuestas por la propia lógica de cooperación internacional de "ayuda oficial al desarrollo" de matriz Norte-Sur con hegemonías neoliberales y monoculturales.

4- Que en este marco, el debate sobre la Cobertura Universal de Salud (UHC), para su instalación como un ODM posterior al 2015 implica una serie de peligros y desafíos a visibilizar en este escenario internacional, regional y nacional de nuestras sociedades. Las tensiones evidenciadas en esto implican:

* Que la UHC sea un camino de relanzamiento de la lógica y planes de "aseguramiento en salud" y ampliación de mercados para la acumulación de capital en el campo de la salud colectiva, de instalación de seguros "asistenciales-curativos" de cobertura de la enfermedad, con paquetes mínimos o básicos de "garantías explícitas", a través de prueba de medios demostrando quién es "pobre" o no para recepcionar "el beneficio", de gerencia

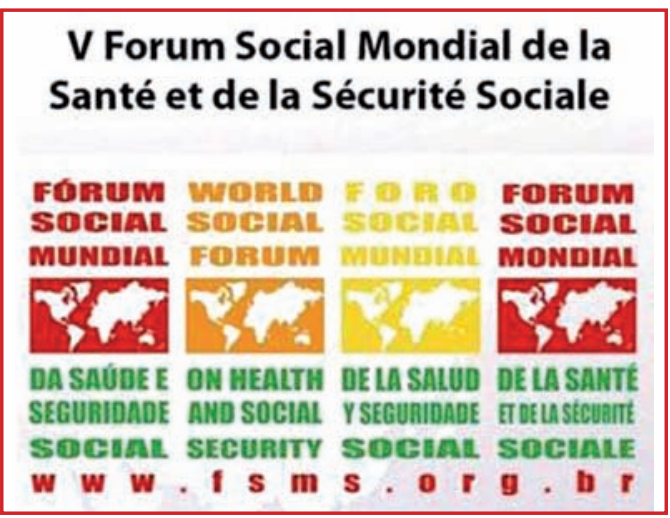

y competencia mix pública-privada y con una primacía de mercantilización, privatización y estratificación-segmentación de nuestras sociedades entre: una salud para "pobres" con "pobres seguros", una "salud para trabajadores formales" y una "salud para ricos" con pago de bolsillo pero beneficiándose de un sistema de subsidios, excenciones y tributos regresivos que representan la transferencia de recursos de los pobres para los ricos. Esta cobertura universal sólo profundizará las desigualdades e inequidades en el seno de nuestros pueblos.

Estas propuestas de las tecnocracias del Banco Mundial (BM), Banco Interamericano de Desarrollo (BID) y de la propia Organización Internacional del Trabajo (OIT) con su campaña de "pisos mínimos de protección social" capturando a un sector incluso del propio movimiento sindical mundial, a muchas organizaciones de sociedad civil internacionales, no son un camino de respuesta para los problemas, necesidades y prioridades de protección de la vida en nuestros pueblos.

* Que no nos confundan las palabras: "Cobertura Universal de Salud", "Protección Social de Salud", "Acceso financieros a Servicios de Salud", "Pisos mínimos de Protección social" son todas propuestas que emanan de estas tecnocracias, organismos e intereses geopolíticos internacionales del capital en el mercado de la salud. Sin duda el "acceso universal a la salud" hacia el acceso político a sistemas universales de seguridad social que incluyen la salud en el marco de los deter- 
minantes sociales de la salud postulado por la propia Organización Mundial de la Salud (OMS) podría ser una propuesta importante y fundamental para construir nuevos sistemas de salud universales por una calidad de vida saludable, aunque insuficiente como respuesta a la crisis multidimensional internacional y la interdependencia de derechos. La OMS tendrá el desafío de enfrentarse a estos intereses que priman en otros organismos internacionales multilaterales, del propio gran capital y grupos económicos multinacionales, si efectivamente desea lograr avanzar hacia el derecho a la salud de los pueblos. Sino la propia OMS una vez más quedará atrapada en prerrogativas y reformas vinculadas a la mercantilización de la vida y la salud. La asociación y apoyo de la Fundación Rockefeller a la propia UHC junto a la OMS pareciera ser un camino de alejamiento de la salud de los pueblos.

En este contexto y marco consideramos sustancial:

5- Que desde el FSMS y SS nos volvemos a definir por el desarrollo de Sistemas Universales de Seguridad Social de carácter públicos, universales, integrales e igualitarios, reconociendo la interdependencia de los derechos expresados como necesidades y que plasmen la universalización de derechos de una ciudadanía amplia$\mathrm{da}$ en un sistema de protecciones sociales con ambiciones redistributivas de la riqueza, comportando sistemas únicos universales de salud pública y sistemas universales públicos de previsión y protección social con participación y poder popular en todo el ciclo de formulación, planificación, gestión, control, regulación y evaluación de las políticas públicas.

6- Que desde el FSMS y SS entendemos que es sustancial una refundación de los Estados hacia Estados Sociales de derecho con identidad nacional, con nueva institucionalidad, modelos de gestión, territorialidad y plurinacionalidad, con un claro impulso de la recuperación de la esfera de lo público con protagonismo popular, equidad de género y diálogo intercultural.

7- Que desde el FSMS y SS proponemos que no es posible debatir estos procesos de universalización de derechos sin poner en el centro de nuestra preocupación su financiamiento o sea la economía política del universalismo, producción y distribución. Necesitamos reformas integrales hacia la progresividad y justicia de nuestros sistemas tributarios para efectivamente construir sociedades equitativas hacia el igualitarismo. Proponemos que un ODM post 2015 debería necesariamente definir la justicia tributaria en los ámbitos nacionales y globales, afectando los sistemas aduaneros y los intercambios comerciales internacionales y la eliminación de los paraísos fiscales.

8- Que desde el FSM y SS en este proceso es fundamental repensar y construir nuevas democracias y nuevos Estados, que efectivamente incorporen como principios del Gobierno de los pueblos las modalidades de democracias deliberativas, democracias sociales, donde la justicia social sea el producto obligatorio de la democracia política y donde la contabilidad social se imponga sobre la contabilidad financiera en la gestión estatal, en aras de plenas garantías de los derechos humanos por una calidad de vida saludable, o bien como plantean los pueblos indígenas-originarios-campesinos del Abya Yala de las Américas para impulsar un paradigma del Buen Vivir o Vivir Bien de ecología de saberes, solidaridad, cooperación, complementariedad y cuidado de la vida y en armonía con la naturaleza.

9- Que el FSMS y SS llama y promueve la democratización y des-tecnocratización de todo el proceso de debate y discusión de los postODM 2015, así como de los Pisos de Protección Social y de la "Cobertura Universal de Salud" considerando fundamental la participación real y protagónica de los pueblos (no sólo de las ONGs o agencias internacionales), llamando asimismo a nuestros Gobiernos populares y progresistas del mundo, en especial de América Latina y el Caribe a construir una voz y posición común desde el UNASUR (Unión Suramericana de Naciones), el ALBA (Alternativa Bolivariana de los Pueblos) y la CELAC (Comunidad de Estados de América Latina y el Caribe) para plantear un nuevo paradigma para el desarrollo de nuestras naciones y el vivir bien de nuestros pueblos.

Comité Ejecutivo Internacional Foro Social Mundial de la Salud y Seguridad Social 